\title{
Design of Multimedia-based Digital Storybooks for Preschool Education
}

\author{
https://doi.org/10.3991/ijet.v13i02.8188 \\ Didik Dwi Prasetya $\left({ }^{\varpi}\right)$ \\ Universitas Negeri Malang, East Java, Indonesia \\ didikdwi@um.ac.id \\ Tsukasa Hirashima \\ Hiroshima University, Japan
}

\begin{abstract}
Storytelling is one of the suitable approaches to deliver the right information and build the character education of young children. The story content presented by utilizing multimedia elements is able to offer more attractive and increase interest for children. This paper proposes an ICT approach through multimedia-based digital storybook design with an EPUB reflowable format that can be accessed using various electronic devices, whether desktop, laptop, or mobile. The research subjects are limited to 4-5-year-old preschool children. The research reveals that children were very enthusiastic about storybooks, with or without support from teachers.
\end{abstract}

Keywords—digital, storybooks, multimedia, preschool, education

\section{Introduction}

Education is the right approach to prepare the next generation with the excellent characters. Walsh [1] defines education as the process that prepares young people for their social inheritance and advocates three dimensions of education - development of knowledge, training of mental abilities, and development of character. Almost all countries in the world have the same opinion that kindergarten education is considered very important [2]. However, they are the ones who will become the next generation. Therefore, it is also very important for the kindergarten children themselves to begin to engage in early learning experiences for the provision when they adults. The key role of preschool education for improving educational outcomes has gained international recognition, especially among developing countries [3].

There are several approaches which can be taken to deliver information and apply character education values for pre-school age children, one of the most compelling and effective approaches is through stories. Storytelling is an act of reading or telling a story to children. Storytelling is an engaging activity, "Imaginary worlds are enjoyed not only by those who visit them but also by those who invent." [4]. Storytelling is also used as a learning opportunity to create content and connect it to context. As reported by Sanchez [5], some types of stories can be utilized to develop values 
and morality in preschool age children. The use of stories has become one of the strategies applied in the practice of character education, particularly intended for children and teenagers. To reach the optimal results, character education should be initiated in as early as possible, since early childhood.

Along with the development of the era, the delivery of the story began to be done by utilizing the approach of Information and Communication Technology (ICT). As UNESCO suggests, in order to achieve the EFA goals so ICT approach should be included as a part of formal education at every level [6]. Kindergarten education is one of the most appropriate levels to utilize ICT and this important issue has been investigated and believed to be true in the last decades [7]. Research on the effect of ICT in education has actually been studied for a long time, around the early 1970s, and has increasingly asserted that ICTs could support students in formal education [8]. According to Zaranis [9], the introduction of ICTs in kindergarten education provides more opportunities for children to gain rich, diverse, and positive knowledge.

One form of ICT implementation in the field of storytelling is the use of digital storybooks. In principle, the story's digital book is able to accommodate all the contents of a printed book and supplemented with other digital content that is not in the printed book. The storybook approach presented by utilizing multimedia elements (text, pictures, audio, animation, and video) can provide reinforcement to increase children's motivation. The multimedia used as demonstration and research of learning allow the development of teaching and learning environment [11]. As Hughes [12] said, the multimedia-based learning system approach can effectively achieve resource sharing. According to $\mathrm{Ni}$ [13], teaching approach with adoption of multimedia contents can provide various learning information and make language practice learning effectively.

Until now, there are many children's digital storybooks that can be obtained easily. But it is still rare to find a digital book with a flexible design and emphasize all the elements of multimedia, and more specifically with the Indonesian language. Referring to the current urgency and potential, this paper presents a multimedia storybook design based on multimedia with the EPUB (electronic publication) format that can be accessed flexibly, either through the desktop or mobile devices. Digital book format used in this study is EPUB which is the rich contents and standard format of future books which supports mobile activities, whenever and wherever. The research subjects are restricted to 4-5-year-old preschool children. The research reveals that children were very enthusiastic about storybooks, with or without support from teachers.

\section{Digital Storybooks}

The digital era has brought significant changes in human lives. There are many previously conventional (analog) activities which now can be easily done through digital technology. For example, people used to listen to analog radio networks, but now they have various selections of digital radio network on the internet. It goes hand 
in hand with reading. Nowadays, there are a growing number of people who read digital books which can be accessed easily without having to pay.

In general, a digital book comes in an electronic form, which often called an electronic book, e-book, eBook, e-Book, ebook, digital book, or even e-edition. Although the idea of eBook has existed since the 1960s, there is still much confusion about the basic definition of an eBook [14]. Hughes [15] has stated that the eBook definition has become a subject of renewed interest, "involving more complex than that of merely any digital text read via a glass screen". In principle, an eBook is quite similar to a printed book except for their different media, i.e. paper and electronic [16].

There are many kinds of literature that we find in previous years which states that the digital storybooks (also known as electronic storybooks, electronic talking books or digital books) can be beneficial to children's early learning [17]. According to Glasgow [18], CD-ROM storybooks consists of combining text, sound, and graphics, and it motivates young students to learn beginning reading and writing skills. CDROM story-books make it easy for readers to abandon their strategic use of cueing systems to decode words and read for meaning [19]. The advantages of digital storybooks can be highly motivational for young children [20]. The benefit of the digital storybook is also very much felt, in which they can be used to assist children to learn about text directionality, letter-sound relationships, sight words and comprehension [21].

Digital books are highly utilized in the academic environment. However, the application of eBooks for learning is quite late compared to its existence. Fasimpaur [22] proposed that students find e-books to be "a new and unique medium" and as a result, students often read more when having access to e-books. E-books have been used by young readers [23]. Meadows argued that digital storytelling is the social practice of telling stories that make use of low-cost digital cameras, non-linear authoring tools, and computers to create short multimedia stories [24]. In the context of childhood education, the utilization of digital book is absolutely potential. Digital books are rich in content so that they can support interesting stories. Digital storytelling can also be used to help students organize their thoughts, use reflection in their critical thinking, as their portfolio for the prospective employers, or as a part of a course project [25].

The format of digital books has been known since the establishment of a project called Gutenberg Project. This project is a voluntary project aimed to digitalize, collect and distribute cultural works. Digital books offer various superiorities, such as their mobile characteristic, high availability, and flexible format/can be accessed on many devices (desktop or mobile). Also, digital books have relatively low production cost so that they are less expensive than printed books. Nowadays, there are various digital book formats available. The most used three are PDF, HTML, and EPUB.

\subsection{PDF}

PDF (Portable Document Format) is the earliest format of digital books managed by Adobe system in the form of a proprietary format and then released as an open standard in 2008. The main advantage of PDF is in its fixed-width format which is 
suitable for printing and reading only. On the other hand, it still lacks the ability to support dynamic and interactive content.

\subsection{HTML}

HTML (HyperText Markup Language) is a standard foundation of the web application. The major point of digital books in an HTML format is its uniform accessibility through every web browser, device, and platform. In contrast, HTML does not support content protection which is commonly found in Digital Rights Management (DRM) technology of electronic book.

\subsection{EPUB}

EPUB is an open standard developed by the International Digital Publishing Forum (IDPF). The main advantage of EPUB is its reflowable design and ability to present dynamic contents interactively. EPUB is designed for reflowable content, meaning that the text display can be optimized for the particular display device used by the reader of the EPUB-formatted book. EPUB format became famous for being used by the issuer and also a lot of support from the manufacturer and the device reader application for the reader.

\section{Design of Digital Storybooks}

\subsection{Research Design}

The product that will be produced in this research is an application design of digital storybook. Referring to the product characteristics, this research adopts the model of waterfall software process. According to Pressman [26], the waterfall process model consists of 5 main stages, communication, planning, modeling, construction, and deployment. One of the reasons underlying the selection of this model is based on very well-known requirements, stable product definition, and understood support technology.

The waterfall model is very appropriate to resolve the existing problem with the sequence applied approach. The stages of development model can be described as follows:

1. Communication: The communication is the most important step in the waterfall model process. Communication stage is the initiation of the project and aims to gather the digital storybook requirements specification. So, in this phase, we identify problem domain, product solution, and product requirements specification.

2. Planning: This phase focused on the product planning activities, including estimating, scheduling, and tracking. The main activity of project planning is the process of clearing to complete each activity within a single project. 
3. Modeling: There are two main activities in modeling phase, called analysis and design. We use requirements in the previous phase to establish the software and hardware needed for the proper completion of the project. The following step is the requirements, that are gathered in the previous phase are broken down into logical units so that they will become easy for implementation.

4. Construction: This phase consists of two main activities, namely code, and test. A code is to translate the previous modeling result to machine-readable or software application. Once we successfully get the product application, the next step is to make sure that the product is meeting with the requirements specification through a series of tests.

5. Deployment: The last phase aims to deliver product application broadly so it can be used by the target users. In this phase, we also provide support and feedback from the user.

The phases of the waterfall model of software development carried out systematically and sequentially. Each stage in this model is related, the next stage requires the previous stages as input, and so on until all the stages completed [27]. This characteristic will produce a product that has a higher cohesion because everything in each phase we well understood.

\subsection{Product Description}

The suggested application product is a digital storybook application written in the EPUB open standard format. This digital storybook can be accessed flexibility through a variety of user devices, such as desktop computer, notebook, tablet PC, or smartphone. To read this digital book on their respective devices, the user only needs to provide EPUB readers, such as Apple iBooks, Google Play Books, Amazon Kindle, and Azardi.

This digital storybook product especially targets preschool age children. Therefore, the contents of storybooks are designed to be simple by featuring familiar objects around children, e.g. animals, fruits, and plants. The contents are also accompanied by short texts to provide ease for children in understanding their meanings. However, it does not rule out the possibility to be accessed by teachers, institutions, and the general public as references in preschool education, especially for strengthening character values.

The advantages offered and at the same time characterize the design of this book is to emphasize the content with the composition of multimedia elements, able to adjust the screen size of the user (reflowable), and story content that contains character education for children. The use of multimedia elements in the storybook is expected to be able to provide a strong attractiveness and to motivate children. Open standard digital book approach allows the product to be easily accessible through various digital book reader devices. 


\subsection{Research subject}

To find out the implementation of the digital storybook design, limited tests were conducted on preschool children (4-5 years). The subjects were taken from two partner kindergartens, each located in the suburbs and downtown of Malang, East Java, Indonesia. The selected two categories have at least represented the groups of preschool age children.

The number of students involved in this research was 10 students from each kindergarten. Therefore, since there were more than 10 children in the class, the random sampling approach was utilized in the data collection. This approach was considered appropriate because the children have equal abilities. The assumption was the children can operate a computer and smartphone/computer tablet.

\subsection{Research instruments}

The measuring instrument was used to assess the satisfaction level of users upon the developed digital book products. This instrument was in the form of checklists questionnaire on the product functionality given to the experts and samples of the research partners. Filling the questionnaire instruments for children performed by accompanying teachers by asking them one by one

Table 1. Design of questionnaire for participants

\begin{tabular}{|c|l|c|c|c|}
\hline \multirow{2}{*}{ No } & \multicolumn{1}{|c|}{ Question } & \multicolumn{3}{c|}{ Answer } \\
\cline { 3 - 5 } & & Yes & No & No Idea \\
\hline 1 & Do you like this (model/design) digital storybook? & & & \\
\hline 2 & Is the use of text, images, audio, and video (multimedia) very interesting? & & & \\
\hline 3 & Is this digital storybook easy to use? & & & \\
\hline 4 & Is the read-aloud feature (the sound that read the story) very interesting? & & & \\
\hline 5 & Do you have any plans to use this digital storybook? & & & \\
\hline
\end{tabular}

\subsection{Product Evaluation}

Evaluation is an essential phase to inspect the product compliance with the initial specifications. This phase includes the activities of executing the product in the stipulated condition as well as evaluating the results. The product evaluation was divided into two, namely internal and external evaluations. The internal evaluation was conducted by the product developer team and subjected to further revision; if any. The external evaluation involved experts in the field of material substances and media.

The external evaluation by the media expert referred to the aspects of LORI (Learning Object Review Instrument) 1.5 evaluation developed by Nesbit, Belfer, and Leacock [28]. The aspects developed by LORI comprises content quality, learning goal alignment, feedback and adaptation, motivation, presentation design, interaction usability, accessibility, reusability, and standard compliance. 


\section{Product Development}

The development phase aims to realize the analysis and design findings into a digital storybook application. The product development was done through two supporting editor software, i.e. iBooks Author and Sigil (https://sigil-ebook.com/). Some manual codings such as HTML tags and CSS style settings are also made to customize the digital book design.

\subsection{Development Result}

The development of digital book application emphasized the interface design with clear visual images to achieve children's understanding. The page view came with a design which has been familiarized with children's daily lives, which is expected to be able to draw children's interest. The cover page shows the main image which represents the topic of the story. For instance, the topic of the storybook in Figure 1 is sweeping the floor, and it is entitled as "Aku Bisa Menyapu" (I Can Sweep the Floor).

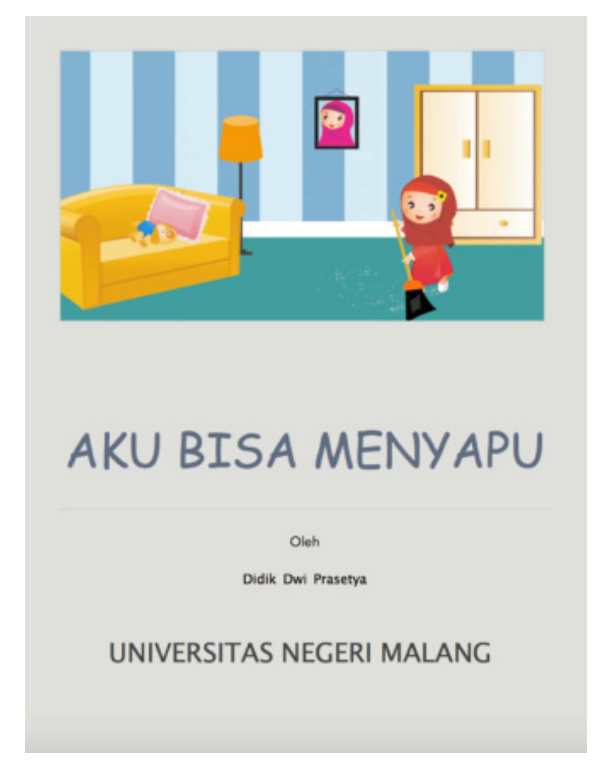

Fig. 1. Cover design result of a digital storybook

However, the structure of the digital book design is still adapting to the general printed book. So, on the first page we will find the cover page, then copyright page, introduction page, table of content page, chapter, and so on. The content page design is made consistent so that it will not distract children's concentration. In accordance with its goal, this book emphasizes moral messages through simple daily stories. The content pages emphasize the theme of the story presented with multimedia elements, such as texts, pictures, animation, and video. Therefore, the story can be more interesting and meaningful for children as shown in Figure 2. 
The advantages of multimedia content are really realized in the design of this digital storybook. Another very interesting content is represented by a short video that presents a meaningful scene. For example, in the story of sweeping the floor, Figure 3 shown the video about how to dispose of the garbage correctly. Aside from being a part of the story, this approach is also expected to play the role of education for children.

Referring to the EPUB 3.0 specification, this digital book design also utilizes one excellent feature, that is very interesting, which is read aloud. This feature represents text-to-speech that can read EPUB text content. Basically, read aloud is playing the recorded audio first in accordance with the text that appears [29]. View of a digital book with read-aloud feature support is shown in Figure 4.

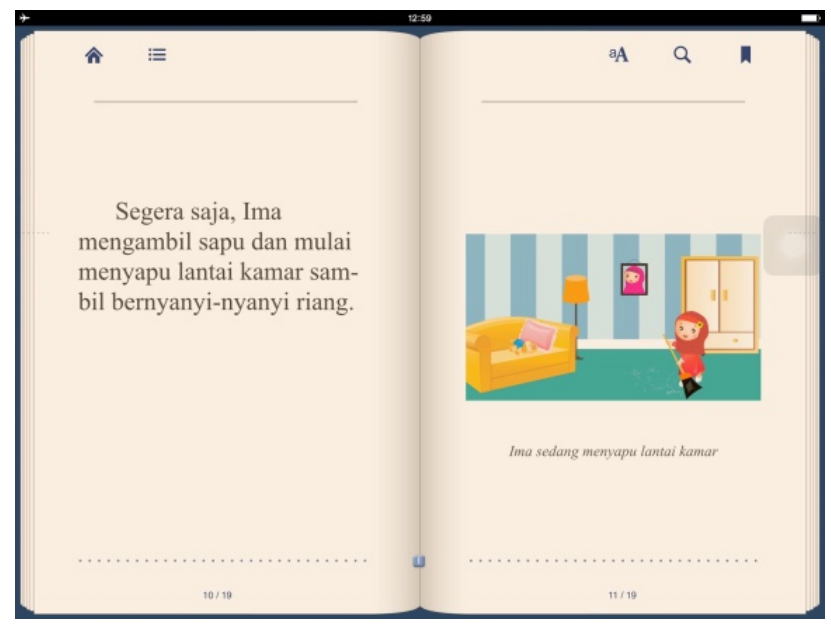

Fig. 2. Text and image content of digital book

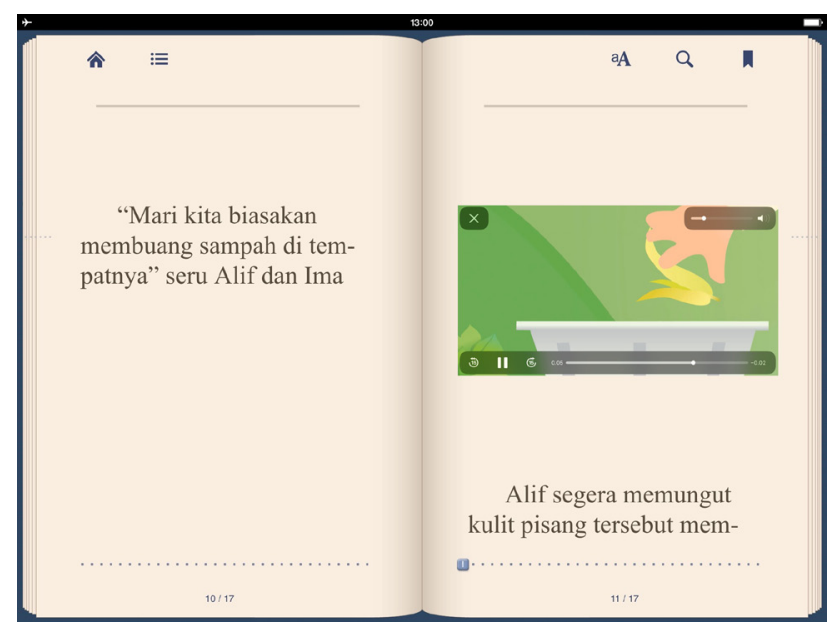

Fig. 3. Video content how to dispose of the garbage correctly 


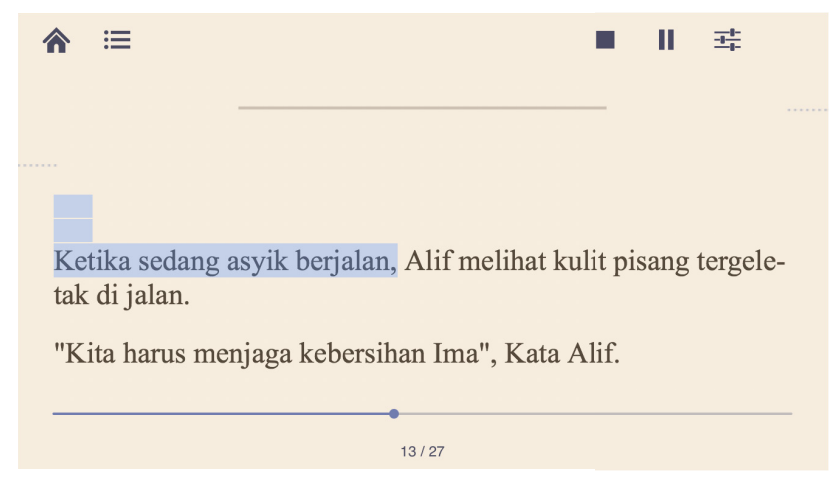

Fig. 4. Digital storybook with read-aloud feature

The read-aloud feature is very useful if children want to access the book without the accompanying their parents because there is an available voice recording that will read the contents of the story.

\subsection{Evaluation Results}

The internal evaluation is conducted by the developer through a series of product functionality testing. The test procedure is performed by running the product and observing the behavior based on the given input. In this test, if the product has responded in accordance with the initial specifications, then the product is declared to work properly.

On the other side, the external evaluation in the form of review or validation was executed by the material and media experts according to LORI instruments. The validation was performed to identify the product validity. It aimed to ensure whether or not the material substances have been appropriate so that the media validity can be identified.

A person with the relevant competence was selected to conduct the material validity test. The chosen material experts are two teachers at Al Hikmah Integrated Islamic preschool/kindergarten, in Malang city, Indonesia. Such material experts have highly relevant qualifications and professions with the developed application.

There were 20 questions used for the material validity test. The reviewer conducted the material validation phase by referring to the instrument provided for material validation. Subsequently, the assessor directly filled her statements based on the evaluation results of the application.

The validation by a media expert was conducted to point out the validity of the learning media so that the level of validity of the media can be identified. This phase involved a competent media expert, a lecturer or practitioner who is competent in the field of computer-assisted learning media. A relevant person has been chosen to perform the product evaluation. The reviewer has qualifications in the field of computer and multimedia assisted learning. Additionally, the reviewer, whose profession is a lecturer in Department of Learning Technology, State University of Malang also has experienced in the fields of academic advisory and learning media industry. 


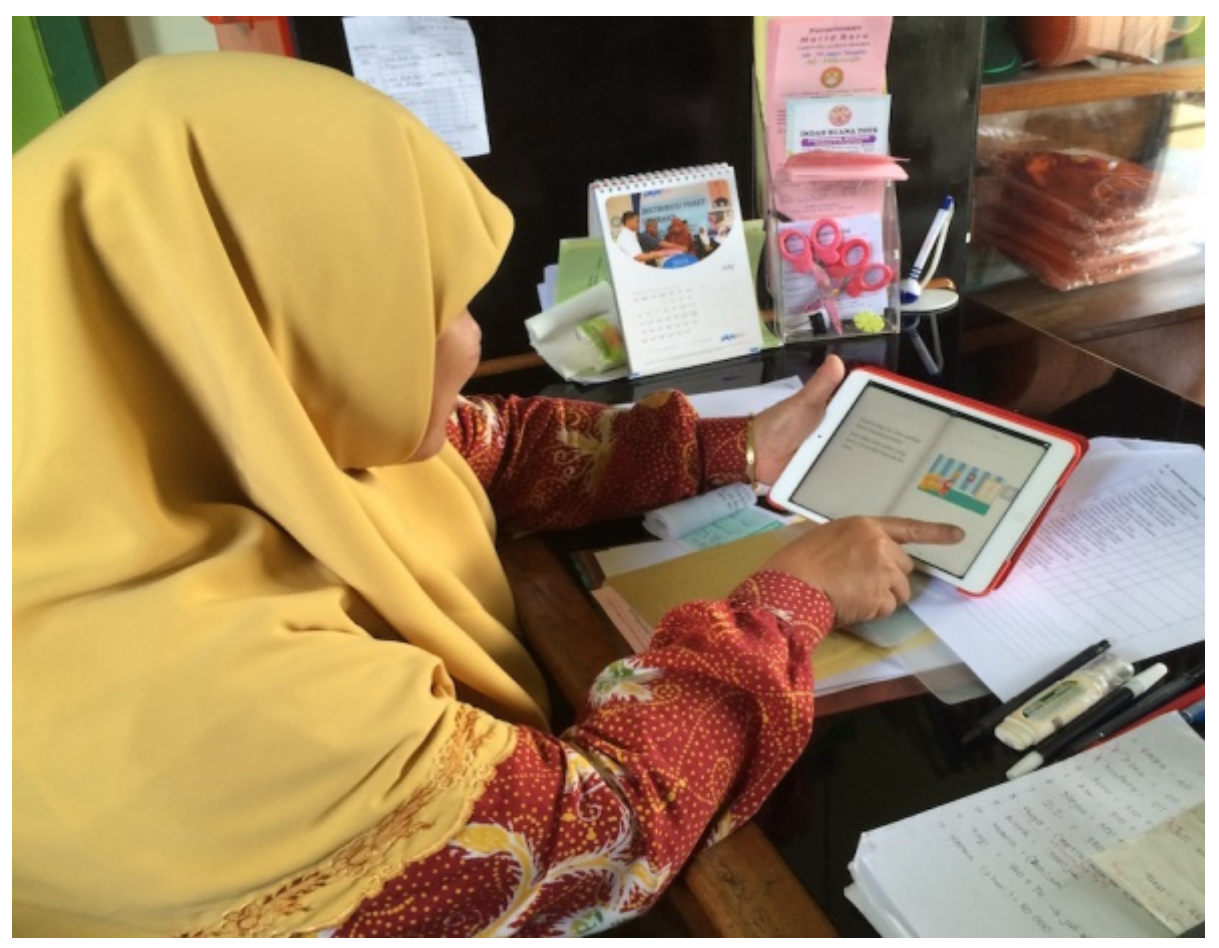

Fig. 5. Content validation by the kindergarten teacher

Once the product design is complete, the next step is to perform limited testing. The first field test was done to 10 students of "Lab" kindergarten (around 4-5 years old) who were randomly selected by their teacher. The test was performed by providing a laptop or desktop computer with the digital storybook application to children as shown in Figure 6. Teachers and the research team guided the students in operating the application. It can be seen that the children were enjoying the presented digital storybook.

The second field test was also done to 10 children of kindergarten in the Al Hikmah kindergarten. In this test, as shown in Figure 7, we focus on the use of tablet PC devices to access the digital storybook. The results of the observation show that the children were more excited to read the provided story.

Overall, both of the field tests held in two different locations shown that children were very enthusiastic and enjoy the story presented in the digital storybook. After the children have tried enough, the next step is to provide a questionnaire to find out the response of the children. In this case, we provided simple statements since the children were still very young and did not know about the specifics of the product.

In order to maintain the objectivity of instrument filling, teacher accompanied the children in turn without any intervention. The teacher would read every item of the statement, such as: "Is this digital storybook easy to use?" the available choices were "Yes," "No," and "No Idea." The teacher then filled the given answers of the children until the finish. 


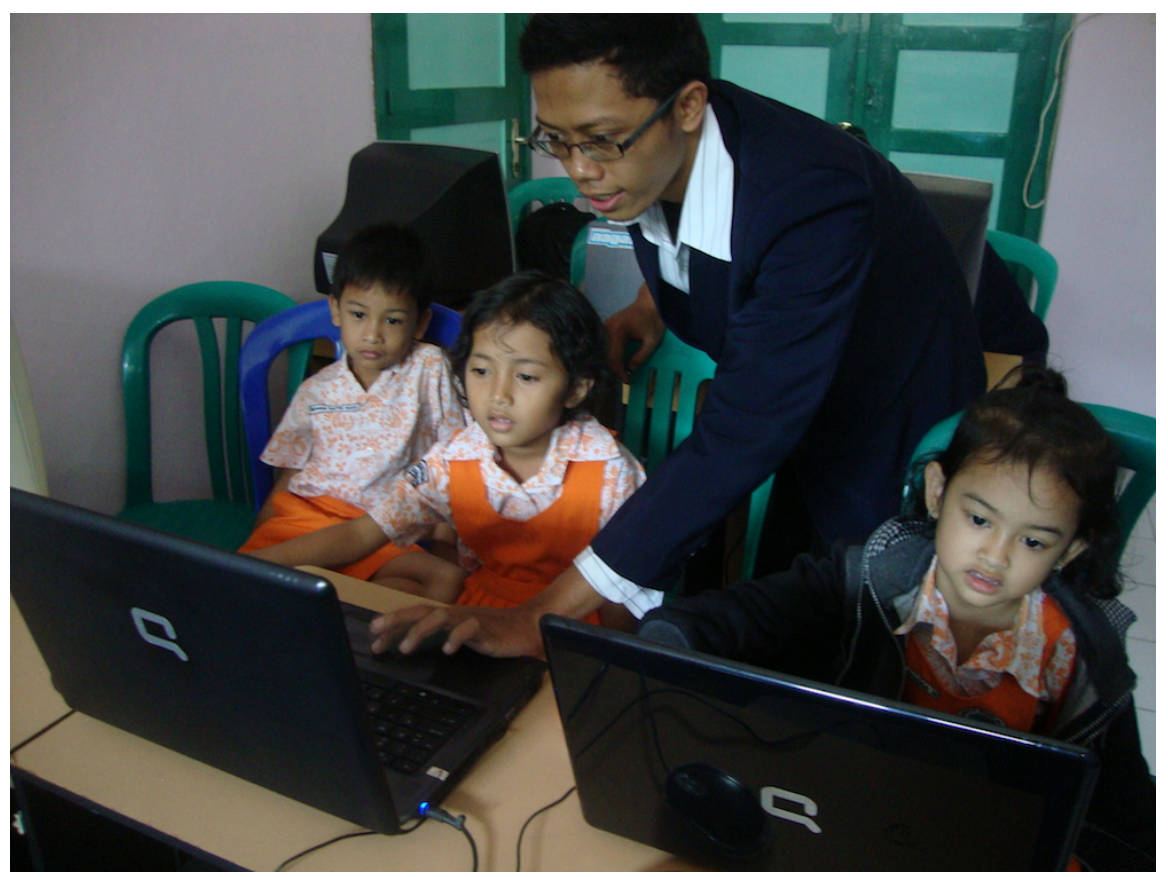

Fig. 6. Field test in preschool children

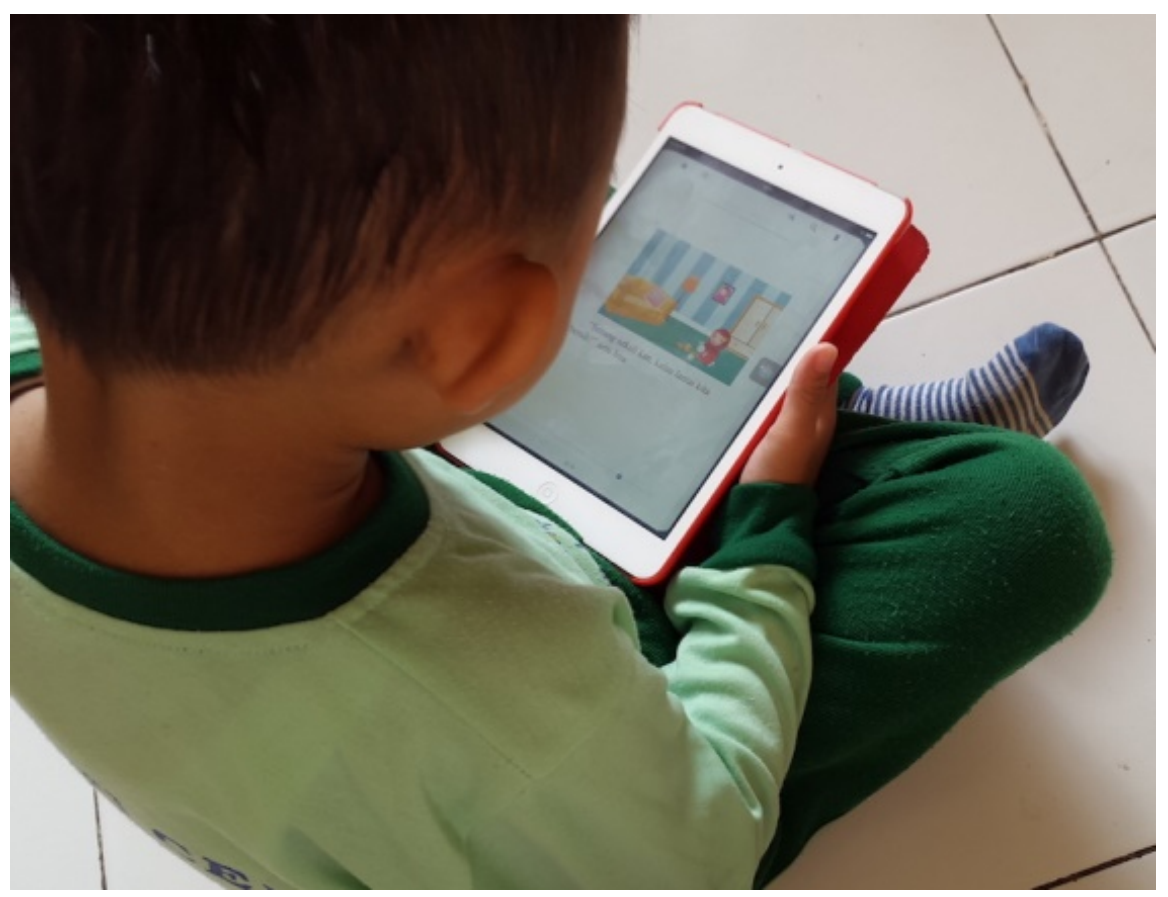

Fig. 7. Product test by using a mobile device 


\subsection{Discussion}

The advancement of digital children storybook application with EPUB format has a strategic potential to be further implemented, especially in Indonesia. This digital storybook can be accessed on various devices (whether desktop or mobile) and can be distributed easily. It also supports the geographic condition and various economic characteristics of the society in Indonesia as an archipelago country.

The use of multimedia elements (texts, pictures, sounds, animation, and video) in the storybooks can produce educative and interesting contents for children. The optimum presentation of such various contents can produce more meaningful stories. It can be seen that the children were very enthusiastic and enjoy the given story.

The results of the evaluation by the material expert which used 20 statements showed an average value of $91.25 \%$. The scores of 4 were given to 14 statements regarding with material substances, language, and writing style and the score of 3 were given to the rest 6 statements.

The results of evaluation by the material expert involving 24 statements shows an average value of $87.5 \%$. The scores of 4 were given to 14 statements regarding with multimedia support, educative characteristic, theme simplicity, the element of character value, and the capability to give motivation, and the scores of 3 were given to the rest 10 statements.

The material expert gave a minor suggestion regarding with sentences simplification in the story to make it easier to be understood by children. The media expert also gave a minor suggestion to clarify and enlarge the pictures to deliver the meaning easily. After the product had been subsequently revised, it was shown to the experts and then tested to the product users.

The results of the first field study involving 10 students by using PC desktop stated that the product is already appropriate for use, with a percentage of $90 \%$. Meanwhile, the results of the field study conducted in the second partner school by using Tablet PC show that the product is appropriate for use, with a percentage of $96 \%$. Therefore, the average percentage of the field tests is $93 \%$ showing a high validity.

\section{Conclusion}

The development results of multimedia-based digital storybooks can be a practical solution to improve preschool age children's knowledge and character values. This approach at least becomes an interesting supplement besides the existing conventional media.

The presentation of simple stories with the themes of daily lives is easy to be understood by children. The representation of story objects using clear text, image, audio, and video elements makes the story more interesting. The read-aloud feature voiced with the kind of children's sounds is getting more and more attention for children and looks very enthusiastic about enjoying the story content. In addition, the moral messages provided in the stories are also very important for motivating children in improving their character values. 
The results of the evaluation point out that the initial specifications of the product are already appropriate for use. Thus, the product could be used on a larger scale to identify its benefits.

\section{Acknowledgment}

We would like to thank the Ministry of Research, Technology and Higher Education of the Republic of Indonesia (through the Ditlitabmas program) and the Department of Electrical Engineering, Faculty of Engineering, State University of Malang (UM), which had full provided support to this research activity.

\section{$7 \quad$ References}

[1] Walsh, K. (1990). The three dimensions of education. Paper presented at the Annual Meeting of the Pennsylvania School Boards Association (Lewisburg, PA, July 19-21).

[2] Drigas, A. S., \& Kokkalia, G. K. (2014). ICTs in Kindergarten. International Journal of Emerging Technologies in Learning, 9(2). https://doi.org/10.3991/ijet.v9i2.3278

[3] Ayvacı, H. S., \& Devecioğlu, Y. (2010). Computer-assisted instruction to teach concepts in pre-school education. Procedia-Social and Behavioral Sciences, 2(2), 2083-2087.

[4] Maxwell, J.C. (1892) A Treatise on Electricity and Magnetism, 3rd ed., vol. 2. Oxford: Clarendon, pp.68-73. https://doi.org/10.1016/j.sbspro.2010.03.285

[5] Sanchez, T. (2005). The Story of the Boston Massacre: a Storytelling Opportunity for Character Education. Social Studies, 96 (6): 265-269. https://doi.org/10.3200/TSSS.96. $6.265-270$

[6] Hinostroza, J. E., Labbé, C., \& Matamala, C. (2013). The use of computers in preschools in Chile: Lessons for practitioners and policy designers. Computers \& Education, 68, 96104. https://doi.org/10.1016/j.compedu.2013.04.025

[7] Stevens, C. (2004). Information and communication technology, special educational needs and schools: a historical perspective of UK government initiatives. ICT and special educational needs: A tool for inclusion, 21-34.

[8] Drigas, A., \& Kokkalia, G. (2014). ICTs and Special Education in Kindergarten. iJET, 9(4), 35-42. https://doi.org/10.3991/ijet.v9i4.3662

[9] Zaranis, N. (2012). The use of ICT in Preschool Education for geometry teaching. In Proceedings of the 10th international conference on computer based learning in science, learning science in the society of computers (pp. 256-262).

[10] Plowman, L., \& Stephen, C. (2005). Children, play, and computers in pre-school education. British journal of educational technology, 36(2), 145-157. https://doi.org/10.1111/ j.1467-8535.2005.00449.x

[11] Wissick, C.A. (1996). Multimedia: Enhancing Instruction for Students. Journal of Learning Disabilities, v29 n5 p494-503 Sep 1996 https://doi.org/10.1177/002221949602900504

[12] Wang, Y., Qi, A., \& Cui, F. (2016). Application of the Multimedia Teaching System Based on Real-time Shooting and Production in Martial Art Course. International Journal of Emerging Technologies in Learning, 11(3). https://doi.org/10.3991/ijet.v11i03.5347

[13] Ni, D. (2017). Design and Research on English Listening Teaching Assisted by Computer Multimedia. International Journal of Emerging Technologies in Learning, 12(1). https://doi.org/10.3991/ijet.v12i01.6053 
[14] Leaf, G (2003). Promoting the uptake of eGbooks in higher and further education. JISC eQ Books Working Group, London. Retrieved from www.jisc.ac.uk/uploaded_documents/

[15] Hughes, C.A. (2003). E-books. In Drake, M.A. (Ed.). Encyclopedia of Library and Information Science (2nd ed.), Marcel Dekker, New York, NY, pp. 984G989.

[16] Van der Velde, W. \& Ernst, O. (2009). The future of eBooks? Will print disappear? An end user perspective. Library Hi Tech, 27(4), 570 - 583. https://doi.org/10.1108/ 07378830911007673

[17] Oakley, G. (2011). Preservice teachers creating digital storybooks for use in early childhood classrooms. In E-Learning (EL 2011) IADIS Multi conference on Computer Science and Information Systems Proceedings, Rome. http://www.iadisportal.org/ihci-2011proceedings.

[18] Glasgow, J., 1996-97. Motivating young readers using CD-ROM storybooks. Learning and Leading with Technology, 24(4), 17-22.

[19] Lefever-Davis, S., \& Pearson, C., 2005. Early readers and electronic texts: CD-ROM storybook features that influence reading behaviors. The Reading Teacher, 58(5), 446-454. https://doi.org/10.1598/RT.58.5.4

[20] Matthew, K. I., 1996. The impact of CD-ROM storybooks on children's reading comprehension and reading attitude. Journal of Educational Multimedia and Hypermedia, 5(3/4), 379-394.

[21] Labbo, L. D., 2000. 12 things young children can do with a talking book in a classroom learning center. The Reading Teacher, 53(7), 542-546.

[22] Fasimpaur, K. (2004). E-books in schools: Check out the reasons why e-books are gaining in popularity in $\mathrm{K}-12$ schools. Media \& Methods, 40(5), 12.

[23] Doty, D. E., Popplewell, S. R. \& Byers, G. O. (2001). Interactive CD-ROM storybooks and young readers' reading comprehension. Journal of Research on Technology in Education, 33(4), 375-385. (EJ635447) https://doi.org/10.1080/08886504.2001.10782322

[24] Meadows, D. (2003). Digital storytelling: Research-based practice in new media. Visual Communication, 2(2), 189-193. https://doi.org/10.1177/1470357203002002004

[25] Carol, L. (2011) Digital Storytelling as an Educational Tool. Indiana Libraries, Vol. 30, Number 1

[26] Pressman, R. (2015). Software Engineering a Practitioner's Approach 8th Edition. The Mc Graw Hill Compannies, Inc.

[27] Prasetya, D. D., Widiyaningtyas, T., Arifin, M. Z., \& I, W. S. G. (2017). Design reflowable digital book template. In AIP Conference Proceedings (Vol. 1887, No. 1, p. 020023). AIP Publishing. https://doi.org/10.1063/1.5003506

[28] Nesbit, J. C., Belfer, K., \& Leacock, T. L. (2004) LORI 1.5: Learning Object Review Instrument.

[29] Prasetya, D. D., Irianto, W. S. G., \& Patmanthara, S. (2016). Desain Template Buku Digital Epub. SENTIA 2016, 8(1).

\section{Authors}

Prasetya, D.D is a lecturer in Department of Electrical Engineering, Faculty of Engineering, State University of Malang (or Universitas Negeri Malang). His main research interest is in software engineering, learning technology, web technology, mobile application, text mining, and big data. He received his master degree from Bandung Institute of Technology, Indonesia. Currently, he prepares to join as a Ph.D. 
student in Learning Engineering Laboratory, Graduate school of engineering, Hiroshima University, Japan.

Tsukasa Hirashima has been a professor of Graduate School, Department of Information Engineering, Hiroshima University since 2004. He received his B.E., M.E. and Ph.D. from Osaka University, Japan.

Article submitted 31 December 2017. Resubmitted 24 January 2018. Final acceptance 06 February 2018. Final version published as submitted by the authors. 